\title{
Research on the Innovation of China Tourism Industry and Sports Industry
}

\author{
Ma Liang \\ Shanghai Jianqiao University \\ Pu Dong New Area, Shang Hai, China
}

\begin{abstract}
In the industrial value chain, Internet development of tourism industry and sports industry has leapt the sports tourism circle, through theoretical analysis of domestic and international sports and tourism industry development of the Internet, explore the development process of the two rigid problem in internet, Innovative construction of the "cross penetration of resources", "common consumption structure upgrading", "industrial chain restructuring" of the industrial chain extension of the interconnected development model. So that it can provide a sustainable impetus for the virtuous circle of the two industries from a new perspective.
\end{abstract}

Keywords-Sports industry; tourism industry; industry value chain; innovation

\section{INTRODUCTION}

With the rapid development of economic globalization and China's economy, the living standard of domestic residents presents a qualitative leap. The pursuit of leisure and entertainment is the true portrayal of this kind of crossing. In this context, the sports industry, which is extended by the pursuit of physical and mental health, entertainment and other needs, has become a sunrise industry. Accordingly, the tourism industry that has experienced local culture, landscape and other core tourism industry also rises, and the cross penetration of the two leads to the emerging industry of sports tourism. But it is undeniable that by analyzing the structure of sports tourism industry, the two symbiosis cornerstone starts from the tension of the industrial value chain extension. In fact, it plays a specific role in the industrial value chain structure, playing different roles and interests demands. Thus, management rights, operation rights and supervision right cross interests in dislocation fusion of the two regional sports industry produces, difficult to effectively match the two resource needs, cross penetration of the vitality of the market reality, in turn, tourism industry high degree of marketization, the homogenization of vicious competition is hard to integrate with low marketization of sports industry. This directly led to the low quality status of sports tourism in the two interconnected industry value chains, and to a large extent ignored the complexity and diversity of the development mode of big sports industry and large tourism industry. Based on this, in the premise of jumping out of the sports tourism industry boundaries, the industry value chain perspective, the author attempts to combine regional economics, strategic management, industrial economics and many other disciplines, integration and development of the two elements of internal inquiry and basic ideas, in order to deconstruction from

Fund Project: Shanghai sports social science research project (TYSKYJ2017001) in 2017 a new point of view and comprehensive construction of the future path China's sports industry and tourism industry in the development of the Internet, and then provide countermeasures to promote the scientific development of the Internet of the two major industries for the government and relevant departments of industry.

\section{LITERATURE INTERPRETATION ON THE INTERCONNECTED DEVELOPMENT OF SPORTS INDUSTRY AND TOURISM INDUSTRY}

\section{A. Definition of the concept of sports industry, tourism industry and sports tourism industry}

The sports industry is the collection of the same kind of economic activities which provide the sports products for the society as well as the synthesis of the same kind of economic sectors. Sports products management includes tangible sports products and intangible sports services; sports economic sectors include not only market enterprises, but also various other kinds of institutions engaged in business activities, such as public institutions, social organizations and even individuals. Tourism industry refers to the comprehensive industry of providing tourism services with the help of tourism resources and facilities. Tourism services include the reception of tourists, transportation, accommodation, sightseeing, shopping, catering and other links. Tourism industry includes three elements: tourism resources, tourism facilities and tourism service. The sports tourism industry refers to the tourist activities carried out by the tourists in order to meet all kinds of sports needs and by the aid of sports organizations or other intermediary agencies. In essence, sports tourism is an important part of sports industry, and it is also a new highlight of tourism development, so it belongs to the economic industry category. ${ }^{[1]}$

\section{B. Research on the situation of interconnected development of foreign sports industry and tourism industry}

In the ways and Strategies of the development of the sports industry and the tourism industry, the research of the developed countries is early, and there are no lack of mature cases which can be used for reference. After concluding, it is believed that the main countries in the study of the two interconnected development are Russia and the United States.

In Russia, the main advantage of the rapid development of the sports industry and the tourism industry comes from the interaction and optimization of the interests of the participants 
in the policy network. According to the translation study of Ma Zhong Li and others, since the late Soviet Union allowed the sports association to carry out business management to Russia's independence, it has issued a series of laws and regulations to promote the development of the sports industry after being a government leader of the market leader and manager. Such as "the 2006-2015 years sports development plan of Russia Federation" and "sports development strategy before 2020 by Russian Federation" all play a strong role in promoting the development of sports industry in Russia. And this kind of boosting has been propelled by the establishment and development of many sports industry clusters in Russia, and Russia has also realized the goal of implementing the sports industry as a sports power. In addition, it is worth mentioning that with the decline of the peak value of the sports industry and the deterioration of the super competitive environment, Russia's sports industry has entered the bottleneck era of industrial development. In the period of breaking the bottleneck, the Ministry of sport and tourism in Russia is leading the world in March 2010, and issued the outline for the development of sports and tourism department (hereinafter referred to as "Outline").The theoretical framework of the program mainly includes four aspects: simplifying the distribution of land and perfecting the laws and regulations of small and medium enterprises in sports and tourism. This doctrine has changed Russia planned economy state monopoly, the small and medium-sized enterprises increased from $17 \%$ to $60-70 \%$, and create conditions to simplify the sports and tourism land use program of small and medium sized enterprises; pay attention to sports industry personnel training and service level; the creation of long-term leasing companies in order to achieve the national sports and tourism equipment purchase management sports industry and tourism industry in the establishment of a unified. In practice, the detailed rules for the implementation of this law by the state financial allocation, improve the national physical exercise and the proportion of students physical exercise proportion, expand the sports population, and thus enhance the consumer groups of sports and tourism industry, to promote the sustainable development of the two interconnected; improve sports and tourism services to small and medium enterprises supervision and evaluation. The supervision and evaluation system clearly stipulates the statistics and supervision standards of 3 evaluation grades. ${ }^{\text {[2] }}$

In the United States, as a large sports population, the development of both professional and amateur sports in the United States plays a leading and guiding role in the world. According to the study of Dong Er Wei et al, due to the neglect of the complexity of the sports industry and tourism industry docking and fusion approach to the diversity of forms, their limitations on the Internet sports industry and tourism industry in the interactive docking of the sports tourism industry, the development of the Internet path two can learn from the two main categories: one category is the Internet the development pattern of products. It mainly relies on four forms, including professional sports tourism, amateur (University) sports tourism, outdoor activities (hunting, fishing, golf), sports related sports tourism activities (visiting sports museums, hall of fame, sports facilities, etc.). The United States occupation sports abnormally developed occupation Sports League corresponding number, of which the most famous are the four major occupation League, every year with the help of these numerous types of occupation League, the audience of more than $1 / 3$ of the population, and the occupation league season for a long time, can affect the continuity of the sports tourism in the market; amateur sports tourism mode, mostly to make full use of College Students' sports activities and Sports Amateur League to enhance the number of sports tourism population to promote the sports industry market depth; and outdoor activities and sports on sports tourism activities is mainly the use of outdoor experience and visit the model promotion. In addition, the second category is the operation model and marketing model of the United States. It has a positive significance on the interactive development of China's sports industry and tourism industry, tourism organization and management of sports in the United States mainly from the non-profit sports management organization, including the Federation of Sports Commission and the National Sports Committee; there is a famous website platform www.visittheusa.com in marketing mode, there is a special plate on the website sports tourism. The four famous sports league events in America can be querying on this website, making all kinds of sports activities become one of the marketing means of sports tourism, reflecting the selling point of sports tourism products. ${ }^{[3]}$

In summary, the benign interaction between Russian sports industry and tourism industry "prescription" from the government departments in the policy network support and supervision to promote the implementation of two-way reinforcement, the two extension of the industrial chain and the upgrading of the structure from external forces, taking into account the interests of the two sports industry and Tourism industry in the subject's own interests, and let the two industry the investment subject to form a full coverage of the interaction. In the United States, the positive factors in the two mode of interconnected development are the multiple functions of the third party organizations and nongovernmental organizations.

\section{Review of the interconnected development of domestic sports industry and tourism industry}

Compared with foreign countries, the research on the interconnection development of sports industry and tourism industry started late in China and the research on the interconnection mechanism between the two is still in the exploratory stage. The traditional mode of development, the development of the Internet mode many studies of the two equivalent of the sports tourism industry, and the fact that sports tourism is the result of the sports industry and tourism industry cross penetration, its essence is the new industries around the sports industry and tourism industry to promote the birth of interconnected rigid. Therefore, from the field covered by the industry value chain, sports tourism industry neglects the motive force caused by the long-run mechanism between the big sports industry and the big tourism industry. At the same time, in the new path of the two interconnection developments, we should discuss the direction of the industrial value chain, covering the research on the interconnection development between the big sports industry and the big 
tourism industry. The inquiry from the CNKI full-text data online journals in different keyword retrieval related research papers in recent years, the retrieval results show only 2 articles, of an Lu Chang Bao et al published in 2011 "sports industry and tourism industry docking mechanism", another one is Lei Bo in 2012 published "China the sports industry and tourism industry interaction and integration mode analysis" research. In addition, the author also tries to search keywords of sports tourism, the results showed that high repetition rate up to 5242, remove the papers, the research involved in sports tourism in China is much higher than the number of sports industry and tourism industry, indicating that the current mode of sports industry and tourism industry development of the Internet is still blank.

\section{THE MAIN PROBLEMS OF THE INTERCONNECTED DEVELOPMENT OF SPORTS INDUSTRY AND TOURISM INDUSTRY IN CHINA}

\section{A. The value alienation of the management system and operating mechanism in the interconnected region}

It is an inevitable trend to interconnect the sports industry and the tourism industry under the law of the market mechanism. On the industrial value chain, the purpose of value creation is to achieve operation and management of the two marginal resources through the market insight of common consumers, and establish a win-win mechanism to achieve common profit. But in terms of sports industry or tourism industry, because of the wide coverage and wide variety of the two areas, it is bound to be difficult to cooperate in the corresponding management system and operation mechanism, and the resource value is difficult to expand. For example, sports venues service industry in the field of sports industry, The majority of China's large and medium-sized sports venues under public stadiums, in nature, is to provide public sports products and services in the stadium, ownership, career sports venues are holding institutions of state-owned assets, the stateowned assets management and implementation of "management methods of state-owned assets of administrative institutions". Therefore, a multi head management model is presented in the management system. Because the ownership of sports venues belongs to the government, the government is in the "big head" management. Many other small businesses include finance bureau, tax bureau, health supervision, urban management law enforcement and safety supervision; On the operational mechanism, the urgent demand from the market supply and demand, most sports service industry has entered the mode of operation of enterprises, enterprise operation includes to spend a lot of resources in the sports management company, sports information technology companies and sports intermediary service companies. In the same way, most of the natural scenery and the ownership of the cultural landscape in the tourism industry belong to the government, and the operation mechanism is commercialized. Obviously, in the fusion of the two interconnected areas, especially in sports and tourism industry value chain, management system and operation mechanism mode respectively represents a group with independent interests, and their common interests between each other, but in the win-win mechanism construction is hard to appear the phenomenon of convergence, so as to realize the value of alienation in the process of pursuit the common value creation and value dilemma.

\section{B. Rigid interconnected graft function is not strong}

Tourism and sports are two closely related social and economic phenomena (Peric, 2010). ${ }^{[4]}$ The main types of the development strategy of the international developed tourism industry mainly include four kinds: One is to rely on existing resources to develop industrial strategy; the two is to integrate development strategy with other industries; the three is to improve and expand tourism complex; the four is the construction strategy of large tourism theme function area, there are many kinds of products in the sports industry. According to the "statistical classification of national sports industry", it mainly includes 11 categories:(1) sports management activities; (2) sports competition and performance activities; (3) sports venues service; (4) sports fitness and leisure activities; [4] (5) sports training and education; (6) sports intermediary services; (7) sports media and information services; (8) other sports related services; (9) sports goods and related products; (10) sports facilities and facilities; (11) sales of sporting goods and related products, trade agents and rentals. Through the integration of two development model after careful study found, the current two way of convergence is mostly focused on the combination of sports competition, sports venues, services and tourism entertainment, far from reaching the full regional integration. Moreover, the two features of rigid interconnection are prominent, and the extensive mode of operation is the main way, which shows the characteristics of poor grafting and grafting. For example, the organizers of tourism industry usually grafted a sports competition product to experience the rigid experience of tourists, while ignoring the multi-level consumption demand of tourists, and the narrow development of the two industries.

\section{Misplacement and lack of cultural orientation of integrated products}

In recent ten years, with the development and promotion of sports tourism market in China, the interconnection development of sports industry and tourism industry has a certain latitude and latitude. It is obvious that the development of the sports tourism market helps the two interconnected drive to a great extent. And the Internet is driving two-way cross penetration, through mutual penetration, the formation of "you have me, I have you" pattern. At the same time, in this pattern, the results of industrial penetration will help to widen the industrial area, gather industrial clusters, integrate the resources of both sides, upgrade their consumption structure, and promote the virtuous circle of sports industry and tourism industry. But it can't be ignored that the penetration and extension of the two will inevitably lead to the new industrial chain, and the cultural positioning of the fusion product under the new industrial chain will naturally become the top priority of the strategic development. But in fact, due to the reality of the two rigid interconnections, there is a misunderstanding in the cultural orientation of the fusion product, and the main form of this understanding bias is dislocation and misalignment. For example, He Nan Song Shan Shao Lin 
Kung $\mathrm{Fu}$ and Zen culture extend the sports culture and creative tourism industry for the creative grafting tourism industry, which directly led to the sharp increase of domestic and foreign tourists, and had a huge impact both at home and abroad. However, the cultural orientation of this characteristic sports culture creative tourism product is still limited to the tourist marketing model of the temple of famous mountain. Thus it can be seen that the misunderstanding of this dislocation has greatly hindered the total visitors' total visit. Dislocation of cultural positioning will inevitably lead to the phenomenon of "not in place", that is, a serious shortage of the corresponding product operation talents, which in turn exacerbates the problem of dislocation and failure.

\section{A TENTATIVE PLAN FOR THE INTERCONNECTED DEVELOPMENT OF CHINA'S SPORTS INDUSTRY AND TOURISM INDUSTRY}

\section{A. Interconnected development model of resource cross penetration}

In essence, the penetration of sports industry and tourism industry resources is an integration of the two industries at the boundary of the existing resources, while the two industry resource cross is the integration of industries through the complementarity and extension of industrial resources. For example, the tourism industry in natural scenic area and artificial scenic fusion in sports competition performance, sports fitness and entertainment industry, exhibition industry, sports stadiums, sports industry and sports lottery industry, shaping the integration of the two elements, the realization of co-existence and mutual glory pattern, unique resource type Internet penetration the development of pattern formation, to improve the attractiveness of value and price force the interconnection of the value of resources. At the same time, with the penetration of interconnected resources, the cross type of integrated products are formed. Such fusion products cross complement the experience of sports entertainment products in tourism and entertainment, sports and gambling services in tourist shopping, and cross penetration marketing channels, greatly reducing the marketing costs of the two. Finally, the transmission of these advantages to consumer groups is bound to greatly improve the perceived profitability of consumer groups, thereby greatly enhancing the virtuous circle of the two industry market.

\section{B. The interconnected development model of general consumption structure upgrading}

Don't doubt that the market - oriented signs of any industry are oriented by consumer demand. The development of the market of sports and tourism interconnected industry is no exception. The mining of consumer demand is the internal drive of the orderly interconnection of the sports industry and the tourism industry. Therefore, in the construction of the two interconnected development model, the first thing to weigh is the problem of the upgrading of the common consumption structure produced by the two interconnections. Therefore, at the level of government and operating institutions, To promote the sustainable development of the sports industry and the tourism industry's interconnection market, we first need to play the role of the government and operation management institutions in the process of the two integration. At the government level, we put forward the guiding ideology of industrial convergence, the corresponding policies and regulations, formulate long-term development plan, guide and supervise the market operation norms and development strategies of the converged enterprises, and encourage enterprises to create public service platform for integrating products. In the operating mechanism and regulation of enterprises, the overall strength of a bigger and stronger Internet market, short board integration of industrial structure research, detailed research the supply structure quality factors of resources cross penetration type, transformation of consumer groups, consumer experience, optimize product structure and then migrate to the fusion, the psychological demand level of consumer groups. To drive consumer groups driving factors; on the other hand, whether it is Internet products supply structure optimization, integration or upgrade industrial structure, to advance and study the market subdivision consumer groups and types, pushing the commonness and homogeneity of Internet consumption patterns, to prevent extensive business in across the old road.

\section{Interconnected development model of Industrial Chain Restructuring}

At present, in China's sports industry, industrial competitiveness is not strong, market level is not high, and industrial chain is not long, which is the dominant feature of its development. However, the tourism industry is facing the difficulties of upgrading development and homogenization and vicious competition environment. Under this situation, the integration of industry and the symbiosis and complementarity of resources in the sports industry and tourism industry form the new interconnected industry ecosystem. It is the consensus of the two industries in the future. Therefore, the two industry convergence can be divided into three types, one is the cross industry convergence mode, the second is the penetration mode of industrial convergence, and the third is the restructured industry convergence mode. The main carrier of the former two kinds of industry integration mode is to cross penetration of resources, and the third fusion model is to extend the industrial chain, restructuring and innovation as the main line, to produce new fusion products or services, the formation of new industrial clusters, creating new creative industry chain. On the specific measures, we first need to point out that the two industry chain restructure is the change of the industrial chain structure, that is, the main object of industrial chain reorganization is from inter enterprises, which is manifested in the change of the number of enterprises, the association of industrial chains and the way of association in the industrial chain. And the kernel driver of this change is innovation. Secondly, in the process of the development of the Internet industry chain model to construct the recombinant type in the first upgrade and the survival of the fittest enterprises on both sides of the industry chain, and then generate a new industrial chain, enterprise combination innovation elements such enterprises and occupy the high-end new industry chain including sports organization and management of The Mobility Company, and the sports fitness sports intermediary service company the tourism industry in 
the field of internet entertainment company, a portfolio management mechanism and mode of recombinant products of both sides, and produce new products supply structure, integration of new products, new marketing channel integration enterprise, expand the new integration model of consumer groups. For example, take the full operation of the Shenzhen Universiade center as an example, Since the Shenzhen Universiade center is located far away from the city, its post competition operation model is a large public stadium which is difficult to solve "cost operation". In the industrialization path into the entrusted operation after the first inter enterprise industry chain restructuring of the company's operation of sports and sports information company, the implementation of smart management approach in the consumer management and marketing mode, to professional sports information companies to jointly develop consumer groups. The core of intelligent management is the transformation of the customary traditional Scan model from the consumer to the Social Scan model. In the upsurge of Internet consumption, it plays a vital role in guiding and even selectively improving consumer's consumption concept and consumer behavior. Such companies use large data platform to filter and select consumption preferences and consumption habits of consumer groups, and then design marketing channels targeted to Windows, special clients, WEB websites, Android mobile APP and other various operation interfaces to serve consumer groups. Next is the industrial chain restructuring of sports operation companies, financial companies and tourism companies. The whole industry chain resources from upstream industry content development to middle and lower reaches activities promotion and derivative business operation and so on. The integration of sports services, fitness, leisure, entertainment, tourism, shopping is an integral part of the urban sports service complex. It not only changed the current situation of the operation loss after the
Shenzhen Universiade center, but also became the new "model" of the interconnected development of the sports industry and the tourism industry.

\section{CONCLUSION}

The main problems of the interconnected development of sports industry and tourism industry in China are as follows: The value dissimilation of the management system and operating mechanism in the interconnected region; Rigid interconnected graft function is not strong; the misplacement and disposition of the cultural orientation of the fusion products.

The idea of the path of China's sports industry and tourism industry interconnected development: The interconnected development model of the cross penetration of resources; The interconnected development model of general consumption structure upgrading; The interconnected development model of industrial chain restructuring.

\section{REFERENCES}

[1] Tianlong Zhong.Introduction to sports service industry [M].Shanghai: Fudan University press,.2008, 6

[2] Zhongli Ma.New initiatives and Inspirations of Russian sports and tourism SME development program [J].Journal of Shanghai Institute of Physical Education, 2012, 36 (6):25-28

[3] Institute of Earth Landscape tourism, American sports tourism for reference to the development of sports tourism in China [EB/ OL],

[4] PERI? MARKO. Sports tourism and system of experiences[J].Touri HospitalManage,2010,16(2):197-206. 